\title{
Au commencement
}

Au commencement, Dieu créa les cieux et la terre. Il peupla la terre de brocolis, de chouxfleurs et d'épinards, de légumes verts, jaunes et rouges de toutes sortes. Ainsi l'homme et la femme jouiraient de longues vies saines.

Voyant les grands cadeaux de Dieu, Satan offrit la farine blanche de blé, le sucre de canne, puis il les mélangea. La femme passa de la taille 38 à 44.

Alors Dieu créa le sain yaourt afin que la femme puisse conserver sa ligne, ligne que l'homme appréciait comme il se doit.

Et Satan créa la double crème glacée Mövenpick et dit: «Voulez-vous du chocolat Lindt avec?» Et l'homme dit «Ouais» et la femme dit: «Avec mon chocolat faites des biscuits aux pépites de chocolat». Tous deux gagnères cinq kilos.

Alors Dieu dit: «Essayez ma salade verte toute fraîche.»

Et Satan offrit l'assaisonnement pour salade à la double crème et le pain grillé au beurre et à l'ail. En fin de repas, l'homme et la femme durent desserrer leurs ceintures.

Alors Dieu dit: «Je vous ai envoyé des légumes sains pour votre cœur et l'huile d'olive pour les faire cuire.»

Et Satan offrit des poissons cuits à la friteuse, du poulet à frire, l'entrecôte si grande qu'elle a besoin de son propre plateau. L'homme pris encore du poids et son cholestérol traversa le plafond.
Alors Dieu créa les chaussures pour courir afin que leurs enfants puissent perdre les kilos supplémentaires.

Et Satan offrit la télé par câble avec télécommande, afin que l'homme ne doive pas faire d'efforts pour changer de canal. L'homme et la femme ont ri et pleuré à la lumière clignotante et ont pris encore quelques kilos.

Alors Dieu apporta la pomme de terre, naturellement pauvre en graisses, et débordante de santé.

Et Satan éplucha sa peau saine et la jeta, découpa en morceaux son centre riche en amidon et les jetta dans sa friteuse. L'homme gagna encore des kilos.

Alors Dieu donna le bœuf maigre pour que l'homme puisse consommer peu de calories tout en satisfaisant son appétit.

Et Satan offrit McDonald et son double cheeseburger. Puis il dit: «Désirez-vous des frites avec?» Et l'homme répondit: «Ouais, mais une super grande portion.»

Et Satan dit: «C'est bon.» Et l'homme fit un arrêt cardiaque.

Dieu poussa un soupir et créa la chirurgie cardiaque avec quatre pontages coronariens.

Alors Satan créa les réseaux de santé ou de médecins (HMOs ...), ce qui causa aussitôt l'exaltation de M. Couchepin.

Dr Dominique Schwander, p.-d., Villars-sur-Glâne Deirdre Coghlan 